\title{
PERINATAL ASPHYXIA WITH ADRENAL HAEMORRHAGE AND SHOCK
}

Dinakara Prithviraj ${ }^{1}$, Suresh $A^{2}$, Anna Mariam Paul ${ }^{3}$

\section{HOW TO CITE THIS ARTICLE:}

Dinakara Prithviraj, Suresh A, Anna Mariam Paul. "Perinatal Asphyxia with Adrenal Haemorrhage and Shock". Journal of Evolution of Medical and Dental Sciences 2014; Vol. 3, Issue 16, April 21; Page: 4197-4204,

DOI: $10.14260 /$ jemds $/ 2014 / 2418$

ABSTRACT: Clinical manifestations of adrenal hemorrhage vary depending on the severity of asphyxia, as well as in coordination of vigorous resuscitation measures in terms of chest compression and respiration resulting in adrenal hemorrhage. Timely diagnosis by ultra sound gives the clinician advantage to take appropriate steps in the management course to save lives and to institute appropriate medicines to bring the baby out from shock. Following-up with serial ultra sounds and monitoring hemoglobin percentage will help in patient management and clinical outcome. At the same time we should keep some differential diagnosis in our follow up.

KEYWORDS : Adrenal, Hypoxic Ischemic Encephalopathy, Neonatal Hemorrhage, Shock.

INTRODUCTION: The neonatal adrenal gland is vulnerable to traumatic hemorrhage. With the correct interpretation of clinical, laboratory and radiographic data the diagnosis can be made nonoperatively.

The exact etiopathogenesis of adrenal hemorrhage of the newborn is unknown. Associated risk factors for adrenal hemorrhage include birth trauma owing to difficult labor or delivery, asphyxia, septicemia, hemorrhagic disorders and hypoprothrombinemia. ${ }^{1}$

MATERIALS AND METHODS: Here we present a case of a term male newborn born by LSCS who on day two of life, developed convulsions and hypoglycemia. On initial evaluation was reported to have bilateral huge adrenal hemorrhage, hence HIE with bilateral adrenal hemorrhage and consumptive coagulopathy was suspected.

A brief review of literature is discussed.

CASE PRESENTATION: A live term male baby weighing 3kgs delivered by LSCS, indication being failed induction with fetal distress on 10.7.10 at 3:10 pm in peripheral hospital. Baby was flaccid and required Ambu bagging and chest compressions for 3-4 minutes. Following this baby improved, APGAR score not known. Subsequently baby was shifted to mother's side and was feeding well. On the second day, baby developed weak cry, poor feeding and reduced activity and was admitted in a medical college NICU.

Baby developed hypoglycemia with convulsions. It was corrected with intravenous glucose and Injection calcium gluconate $(2 \mathrm{ml} / \mathrm{kg})$. Inspite of the above treatment convulsions persisted and phenobarbitone was given, even with these medications convulsions continued hence phenytoin was given. Inspite of all these therapeutic interventions, the convulsions persisted; the baby was subsequently put on midazolam infusion. Baby was noticed becoming pale, having irregular respiration, Spo2 was fluctuating, and hence supplemental oxygen was given, 
Reports showed:

USG brain: normal study

Hemogram: Hb: 19.7g/dl; HCT: 60.7\%; WBC: 21,300c/Cumm; P72, L20, E03;

Platelets: 1.56 lakhs/cumm ; PS :microcytic normochromic blood picture

S.calcium:6.5mg/dl ; Blood urea :52mg/dl ; S.creatinine $0.7 \mathrm{mg} / \mathrm{dl}$,

PT:3 mins; APTT >5mins 2secs(prolonged).

Inspite of all the above therapeutic interventions baby continued to have convulsions and hypoglycemia.

The baby was discharged against medical advice and was admitted in our hospital.

At the time of admission; baby appeared pale, HR -200/min, RR-40-68/min irregular breathing, BP-30/20 mmHg, GRBS- $30 \mathrm{mg} / \mathrm{dl}$, Temp- Hypothermic, CFT more than 5 seconds, icterus up to lower thighs, pupils mildly dilated and reacting to light.

\section{Systemic examination:}

Cardiovascular System - feeble peripheral pulse, tachycardia with no murmur ; Respiratory system- irregular respiration ; Per Abdomen - soft, distended abdominal girth measuring 36 cm with bilateral huge mass in the flanks ?renal origin ; Central Nervous System - weak cry, hypotonic .

Baby was developing multifocal convulsions.

Hypoglycemia was corrected by administering intravenous $10 \%$ dextrose .Shock was treated with $20 \mathrm{ml} / \mathrm{kg}$ NS.

Baby was put on Bubble CPAP with FiO2 60\%, pressure of $4 \mathrm{~cm}$ of H2O. Intravenous Calcium gluconate was administered at a dose of $2 \mathrm{ml} / \mathrm{kg}$ and inotropes was started.

REPORTS: Hb: 17.8g/dl, HCT: 51.8\%, WBC: 15400c/cumm, Platelets:1.3 lakhs, CRP: negative, Urea: $49 \mathrm{mg} / \mathrm{dl}$, S.creatinine: $0.56 \mathrm{mg} / \mathrm{dl}, \mathrm{Na}: 133.9 \mathrm{mg} / \mathrm{dl}, \mathrm{K}: 3.7 \mathrm{mg} / \mathrm{dl}, \mathrm{Cl}: 106 \mathrm{mg} / \mathrm{dl}$. LFT: normal study. S.calcium: $8.6 \mathrm{mg} / \mathrm{dl}$. TSH: $4.07 \mathrm{micro} \mathrm{IU} / \mathrm{ml}$. Bilirubin: $14 \mathrm{mg} / \mathrm{dl}$;

USG Brain - normal study

USG Abdomen revealed bilateral huge adrenal hemorrhage on right side measuring $3.6 \mathrm{x}$ $3.1 \mathrm{~cm}$; left side measuring $1.5 \times 1.3 \mathrm{~cm}$. (Fig. 1).

At this juncture, HIE with bilateral adrenal hemorrhage and consumptive coagulopathy was suspected. Baby was treated with $2 \mathrm{mg}$ Injection Vitamin K IV and hydrocortisone. Group specific fresh frozen plasma was started and continued for 3 days. Gradually the hydrocortisone was tapered over 4-5 days. Baby was passing urine \& stools adequately. Blood glucose was monitored meticulously and was maintained within normal limits.

Inotropes were gradually tapered and stopped. Baby was removed from Bubble CPAP and started with supplemental 02. Electrolytes were monitored on alternate days which were normal. Phototherapy was given for six days. Sp02 was normal and hence 02 was stopped. There was no evidence of external hemorrhage like petechiae, purpura or internal hemorrhage like hematuria, nasal, oral and GI bleeding. 
Baby's general condition improved, convulsions controlled, injection eptoin stopped, low dose of phenobarbitone $3 \mathrm{mg} / \mathrm{kg}$ HS dose was continued for one month.

BP and blood glucose were maintained. Since serum bilirubin and hemoglobin were within normal limits $(10 \mathrm{mg} / \mathrm{dl})$ and $(15 \mathrm{~g} / \mathrm{dl})$ respectively, so at this point we were forced to suspect cystic neuroblastoma or duplicating renal collecting system.

USG abdomen repeated once in three days, revealed mixed echoic collection texture in adrenal glands bilaterally.

Urinary analysis for VMA - normal

CT scan revealed bilateral adrenal hemorrhage (Fig: 4-8)

Repeat USG revealed left side adrenal hemorrhage which was decreasing in size and the right side collection showed gradual organization. (Fig: 2)

Eye test - normal; Hearing test - Normal

ECG- normal; ECHO - Normal; Repeat USG brain: Normal.

Baby was treated in NICU for 11 days, discharged with syrup phenobarbitone for one month in gradual decrement. Parents were advised about the adrenal crisis symptoms. (Vomiting, diarrhea, lethargy, apnea, not accepting feeding, irritability, not gaining weight, sudden shock like features).

\section{Follow up after 1 month:}

Vitals and blood glucose - normal

EEG- normal. Blood glucose normal. Clotting factors -normal. Blood pressure-normal. Electrolytes normal.

No history of vomiting/diarrhea/shock was noticed in the baby.

Phenobarbitone was stopped gradually.

USG Abdomen:- Left side adrenal- normal, Right side adrenal - the collection was organizing and decreasing in size . (Fig: 3)

\section{Follow up after 2 months}

USG Abdomen: - Left side adrenal - normal, Right side adrenal - size of hemorrhage was decreasing in size. Mild calcification noted.

T3, T4, TSH : normal, PT, APTT : normal. Electrolytes normal.

\section{Follow up at $31 / 2$ months}

Other vitals and blood glucose - normal

USG Abdomen left side adrenal - normal, right side adrenal hemorrhage well organized and was reducing in size noted. Mild calcification noted.

PT, APTT: normal. Electrolytes normal. Baby was noticed to have attained neck control. 


\section{CASE REPORT}

CT ABDOMEN (PLAIN AND CONTRAST) AND ULTRASOUND ABDOMEN IMAGES:

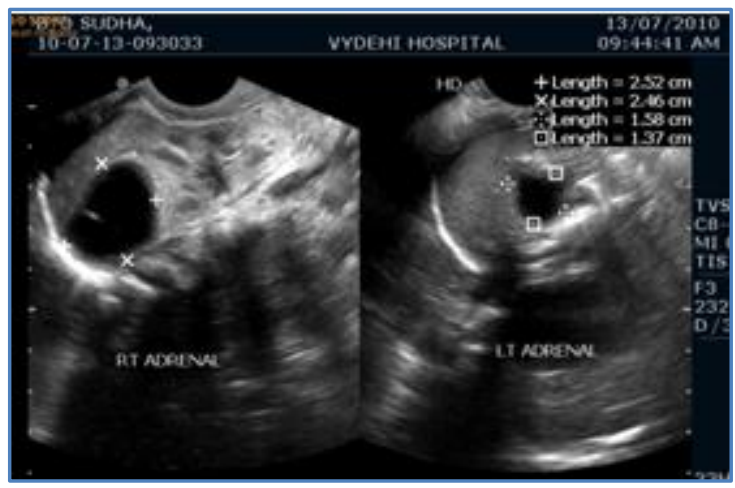

Fig. 1: USG ON DAY OF ADMISSION REVEALING BILATERAL ADRENAL HEMORRHAGE

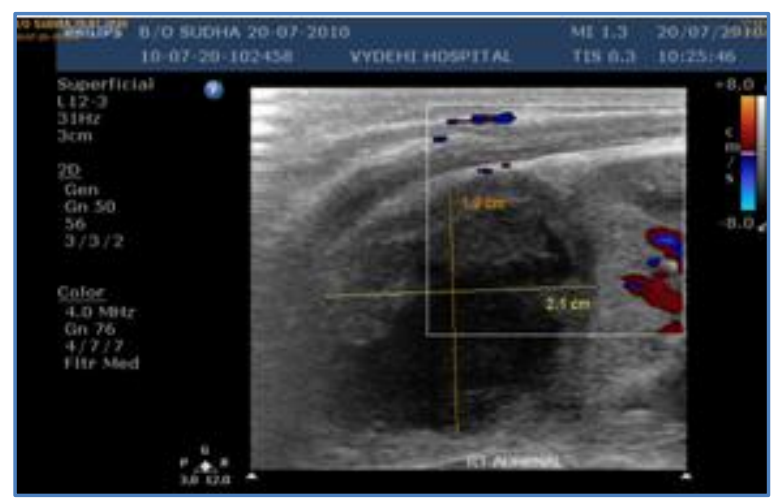

Fig. 2: REVIEW USG AFTER 1 WEEK REVEALING ADRENAL HEMORRHAGE DECREASING IN SIZE WITH GRADUAL ORGANIZATION

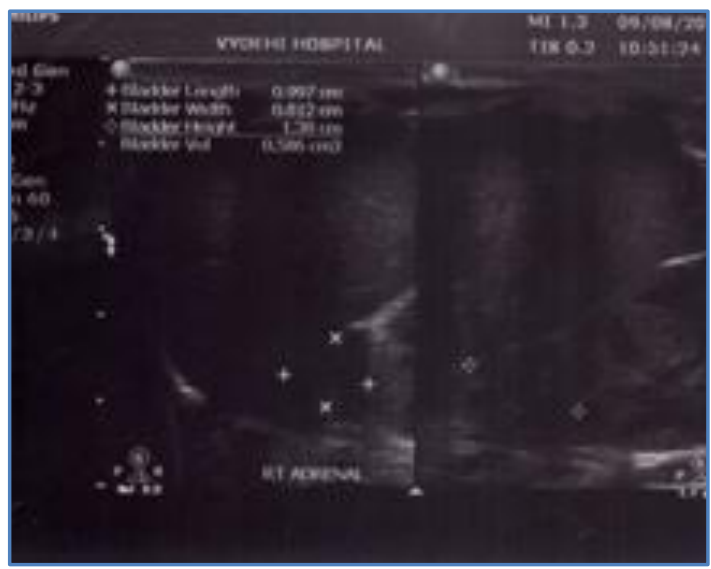

Fig. 3: USG AFTER 25 DAYS REVEALING LEFT SIDE - NORMAL, RIGHT SIDE - ORGANIZING AND SIZE IS DECREASING 


\section{CASE REPORT}

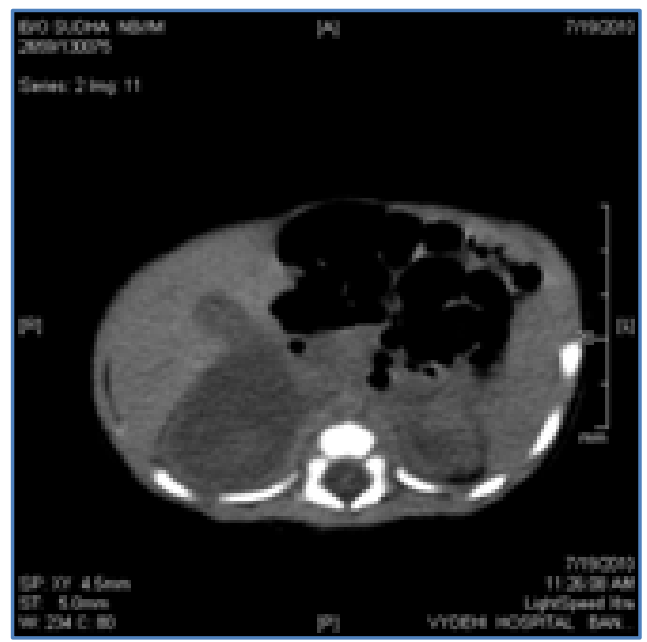

Fig. 4: CT ABDOMEN POST CONTRAST REVEALING BILATERAL ADRENAL HEMORRHAGE

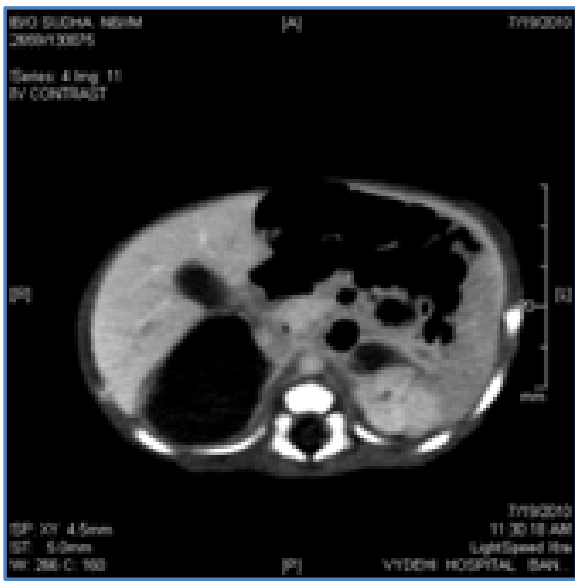

Fig. 5: CT ABDOMEN POST CONTRAST REVEALING BILATERAL ADRENAL HEMORRHAGE

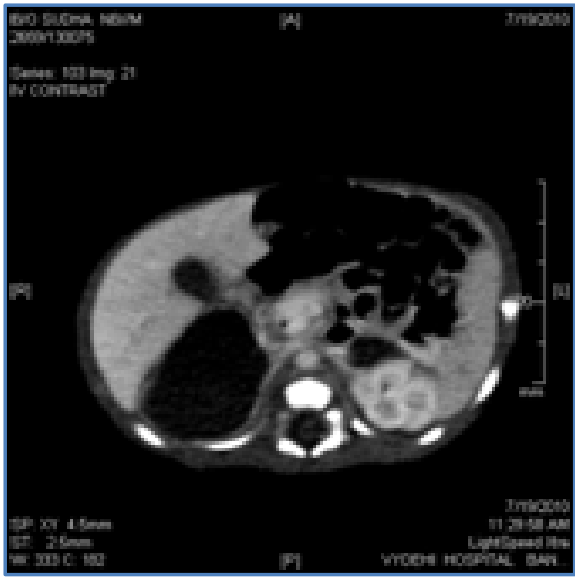

Fig. 6: CT ABDOMEN POST CONTRAST REVEALING BILATERAL ADRENAL HEMORRHAGE 


\section{CASE REPORT}

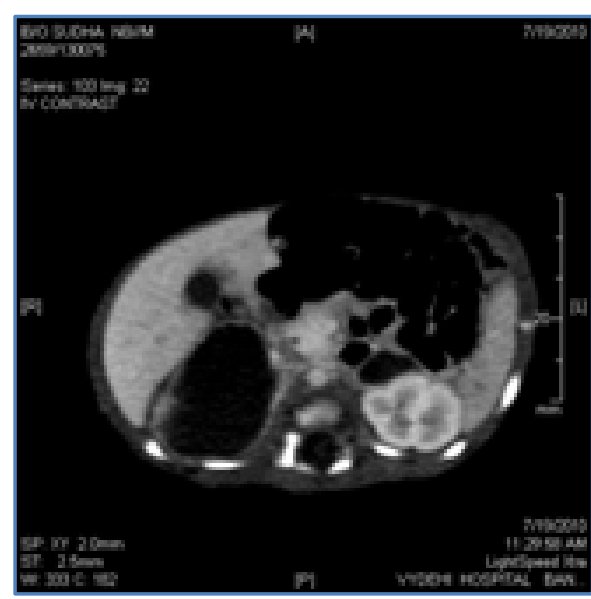

\section{Fig. 7: CT ABDOMEN POST CONTRAST REVEALING} BILATERAL ADRENAL HEMORRHAGE

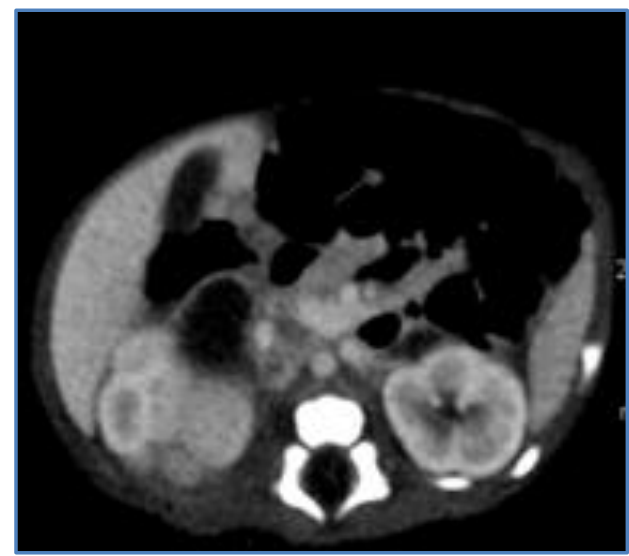

Fig. 8: CT ABDOMEN POST CONTRAST REVEALING BILATERAL ADRENAL HEMORRHAGE

DEPARTMENT OF FADIODLANOSIS \& IMAGING

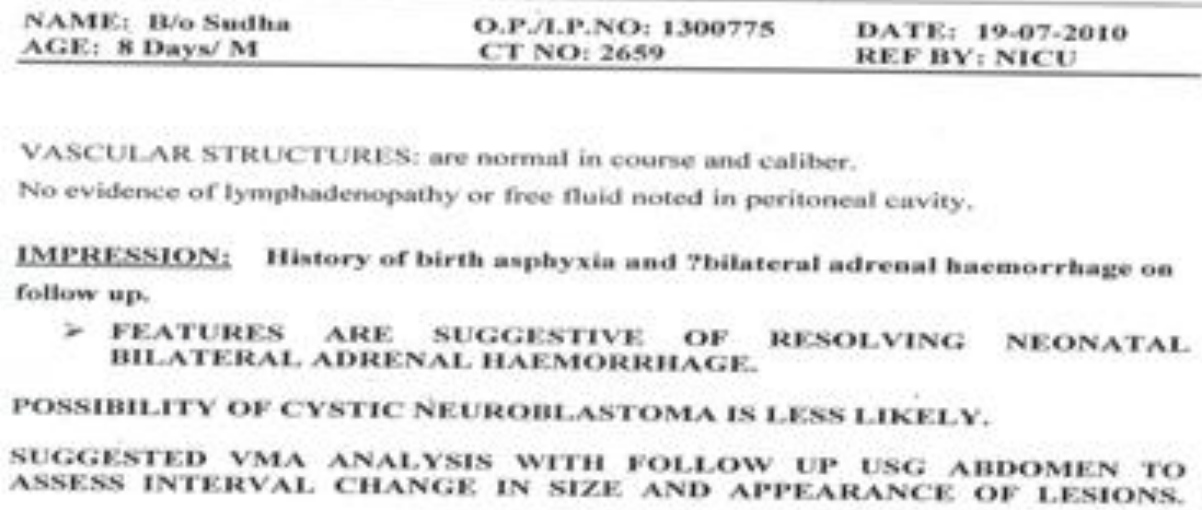

\section{Figure 9}


DISCUSSION: Neonatal adrenal hemorrhage is a well-known clinical entity. Birth trauma, prolonged labor, hypoxia, asphyxia, shock, septicemia and hemorrhagic disorders are known to predisposing factors. The right adrenal gland is involved three to four times more than the left due to its greater likelihood of compression between the liver and spine. Since the right adrenal vein usually drains directly into the inferior vena cava, compression is likely to induce venous pressure changes. The clinical presentation is variable; infants may be asymptomatic, with the diagnosis made incidentally. Clinically common symptoms seen are poor feeding, vomiting, persistent jaundice, anemia, and abdominal mass though there are cases where it is an incidental finding. ${ }^{2}$

Ultrasonography is the modality of choice for initial diagnosis and follow-up for evaluation of a flank mass in a neonate for the following reasons: (a) the small patient size, (b) the relatively large size of the normal adrenal gland in this age group, and (c) the lack of ionizing radiation. Ultrasound examination can be repeated frequently without causing any harmful effect to neonates. ${ }^{3}$

In neonates, the normal adrenal glands are clearly visualized at ultrasound and consist of a hypoechoic cortex and a thin; echogenic medulla ${ }^{4}$ Radiological appearance varies depending on the age of hematoma. While acute hematomas appear echogenic on ultrasound, they liquefy with time and assume a cystic appearance. They shrink and decrease in size and may calcify with aging. Generally, the hemorrhage spontaneously undergoes resorption within four to six weeks. ${ }^{5}$

Thus, ultrasound follow-up is of great importance for ruling out neuroblastoma. Although there is no specific ultrasound sign for adrenal hematoma, demonstrating a decrease in lesion size and observing echo changes that are expected to take place in relation with the age of the lesion may suffice for the diagnosis of adrenal hematoma by ultrasound without any need for further imaging. In general, development of adrenal hemorrhage over time is routine and calcification of the adrenal gland is usually noted approximately two weeks after the hemorrhage or even as early as one week after hemorrhage begins. ${ }^{6}$ The diagnosis of an adrenal hemorrhage has been made when an echo lucent mass was found and then disappeared on follow-up ultrasound studies. Color Doppler sonography may be useful in some cases of neonatal adrenal hemorrhage that are characterized by diminished or absent blood flow in contrast to neuroblastoma. Thus, ultrasound follow-up is of great importance in ruling out neuroblastoma. ${ }^{7}$

Differential diagnoses of cystic lesions near or at the adrenal gland include adrenal hemorrhage, adrenal cyst, adrenal abscess, neuroblastoma, enteric cyst, splenic cyst, and cystic lymphangioma. ${ }^{8}$ Some cysts arising from the upper pole of the kidney may be similar in the image investigation, including duplication of the renal collecting system, hydronephrosis, multicystic dysplastic kidney, Wilms' tumor, and cystic nephroma. Since neuroblastoma is a relatively frequent neonatal malignancy, it is certainly important to distinguish between neonatal adrenal haemorrhage and neuroblastoma.Colour Doppler sonography is useful in some cases of neonatal adrenal haemorrhage that are characterized by diminished or absent blood flow in contrast to neuroblastoma. ${ }^{9}$

This case should alert pediatricians and neonatologists as the symptoms being presented may be distracting and simple but prompt action and evaluation at the right time is life saving and prevents further deterioration of the newborn. 


\section{REFERENCES :}

1. Taeusch HW, Ballard RA, Gleason CA. Renal Vascular Disease in the Newborn. Avery's Diseases of the Newborn 8th edn; 2006; 1320-1326.

2. Goth T, Adachi Y, Nounaka O, Mori T, Koyanagi T. Adrenal hemorrhage in newborn with evidence of bleeding in utero. J Urol 1989; 141: 1145-7.

3. Marino J, Martinez-Urrutia MJ, Hawkins F, Gonzalez A. Encysted adrenal hemorrhage. Prenatal diagnosis. Acta Ped Scan 1990;79:230-1.

4. Lee W, Comstock CH, Jurcak-Zaleski S. Prenatal diagnosis of adrenal hemorrhage by ultrasonography. J Ultrasound Med 1992; 11: 369-71.

5. Lin JN, Lin, GJ, Hung IJ, Hsueh C. Prenatally detected tumor mass in the adrenal gland. J Pediatr Surg.1999; 1620-23.

6. Noe HN, Angel C. Adrenal hemorrhage in the newborn with evidence of bleeding in utero. J Urol 1992;147:1627

7. DeSa DJ, Nicholls S. Hemorrhagic necrosis of the adrenal gland in prenatal in prenatal infants: a clinico-pathological study. J Pathol 1972; 106: 133-49.

8. Naidech HJ, Chawla HS. Bilateral adrenal calcifications at birth in a neonate. Am J Roentgen 1983; 140: 105-6.

9. Strouse PJ, Bowerman RA, Schlessinger AE. Antenatal sonographic findings of fetal adrenal hemorrhage. J Clin Ultrasound 1995; 23 : 442-6.

\section{AUTHORS:}

1. Dinakara Prithviraj

2. Suresh A.

3. Anna Mariam Paul

\section{PARTICULARS OF CONTRIBUTORS:}

1. Associate Professor, Department of Pediatrics, VIMS \& RC.

2. Assistant Professor, Department of Radiology, VIMS \& RC.

3. Post Graduate, Department of Pediatrics, VIMS \& RC.

\section{NAME ADDRESS EMAIL ID OF THE} CORRESPONDING AUTHOR:

Dr. Dinakara Prithviraj,

Vydehi Institute of Medical Sciences and

Research Centre,

\#82, EPIP Area, White Filed,

Bangalore - 560066.

E-mail: drdinakar.nishanth@gmail.com

Date of Submission: 27/03/2014.

Date of Peer Review: 28/03/2014.

Date of Acceptance: 04/04/2014.

Date of Publishing: 16/04/2014. 